\title{
With the past under your feet: on the development of time concepts in archaeology
}

\section{Cristián Simonetti}

\section{(2) OpenEdition \\ 1 Journals}

Electronic version

URL: http://journals.openedition.org/aa/1306

DOI: 10.4000/aa.1306

ISSN: 2357-738X

Publisher

Programa de Pós-Graduação em Antropologia Social (UnB)

\section{Printed version}

Date of publication: 1 December 2014

Number of pages: 283-313

ISSN: 0102-4302

\section{Electronic reference}

Cristián Simonetti, "With the past under your feet: on the development of time concepts in

archaeology", Anuário Antropológico [Online], v.39 n.2 | 2014, Online since, connection on 28 April 2021. URL: http://journals.openedition.org/aa/1306 ; DOI: https://doi.org/10.4000/aa.1306

\section{(c) (i) (9)}

Anuário Antropológico is licensed under a Creative Commons Atribuição-Uso Não-Comercial-Proibição de realização de Obras Derivadas 4.0 International. 


\title{
With the past under your feet: on the development of time concepts in archaeology
}

\author{
Cristián Simonetti \\ Pontificia Universidad Católica de Chile \\ University of Aberdeen
}

\section{Introduction}

If there is something fundamental about archaeology, it is that it deals with time. As its name suggests, it is interested in what is ancient and therefore past. Even though there are other sciences that share this interest, archaeology is characterized by a particular set of practices that makes it unique. These practices seem to have an influence on the way time is conceptualized in archaeology, which contrasts with other scientific and non-scientific understandings of it. But what are exactly those differences? Do they vary among different scientific traditions carried out in different languages? In this article I show that the practice of excavation and the use of stratigraphy have influenced the way archaeologists think about time. By paying attention to speech and gestures, I show that sometimes archaeologists conceptualize the past not as being behind themselves but under their feet, and that time tends to run vertically from bottom to top. Particularly interesting is the experience archaeologists have of travelling downward through time into the past. This way of conceptualizing time contrasts with how non-academics, other scientists and archaeologists from other societies, think about time. The analysis suggests that archaeologists' conceptualizations of time, like presumably those of many other scientists, are not mere abstract categorizations but processes that are coherent and continuous with their sentient experience, as archaeologist learn to appropriate their environment through corporeal movement in practice. This presents a challenge to some widespread understandings of conceptualization, particularly in cognitive linguistics, where the relationship between different conceptual domains, like time and space, is understood as a process of mapping what are initially discontinuous experiences.

In recent years, archaeology has come to realize that understanding others' past and present depends on how scientists working with the past conceptualize time (see, e.g., Shanks \& Tilley, 1987; also Karlsson, 2001:46; Lucas, 2005:28). Even though there has been some progress in understanding how concepts of time in archaeology relate to stratigraphy (see, particularly, Thomas, 2004 and 
Lucas, 2005), until now no attempts have been made to study systematically how archaeologists speak and gesture about time. To the contrary, discussion has been dominated by general philosophical antinomies that, even though they shed light on the contrast between 'our' everyday experience of time and its measurement, do not do justice to human diversity (e.g., McTaggart's A and B series, Bergson's duration and succession, Husserl's flux and representation, Heidegger's time and temporality, and much that came after Aristotle's discussion of Zeno's paradox. See, e.g., Gosden, 1994; Thomas, 1996; Karlsson, 2001; and partially Lucas, 2005; also Gell, 1992). Moreover, discussion of the conceptualization of time tends to be diverted into other issues that do not address the problem directly, such as the study of the different time scales at which archaeological sites can be studied (see, e.g., Murray, 1999; Bailey, 2007).

From another point of view, this limited understanding is partially due to the fact that no ethnographic work has been carried out on this topic. Studies of archaeological practice are already available (see, e.g., Edgeworth, 2003, 2006; Goodwin, 1994). However none of them has paid systematic attention to how concepts of time are used in archaeology. Here I provide a detailed analysis of temporal expressions widely used in archaeology conducted in Germanic and Romance languages, such as English and Spanish, as well as their contrast with expressions used by archaeologists working in East Asian languages, such as Japanese. These contrasting ways of talking about time will reveal important implications for how knowledge is constituted in archaeology, and other related sciences. ${ }^{1}$

It is worth noting that, although there is a multiplicity of temporal expressions in archaeology that deserve careful attention, including certainly those related to the deterioration and conservation of material remains, this article concentrates on expressions that relate to the use of stratigraphy, bearing in mind the relevance most archaeologists attribute to the introduction of stratigraphic methods for the establishment of archaeology as a modern science, mainly throughout the $20^{\text {th }}$ century (see, e.g., Harris, 1979). Stratigraphy was partially responsible for facilitating a more 'objective' understanding of the past, 'as if' from nowhere (Thomas, 2004). Interestingly, this narrative coincides with how some of the temporal dichotomies imported from philosophy, listed above, tend to draw a line between a pre-conceptual experience of the passage of time and its subsequent measurement, mainly through science and technology. However, as the analysis below shows, in archaeology both experiencing and measuring time depend on how archaeologists appropriate their gravitational environments through practice. 


\section{As we move deeper in time}

The fact that archaeologists work with past remains is probably one the most important characteristics of the discipline. ${ }^{2}$ Interestingly, many archaeologists experience the study of the past as a journey. As a Chilean archaeologist told me once: 'doing archaeology is like travelling in time'. We might easily think that all humans have a similar experience of travelling in time, as we all experience its passage. However, archaeologists do not seem to refer to this experience when they talk about the idea of travelling in time. Archaeologists, like many other scientists of time (such as historians), do things most people would not do on a daily basis, or at least without the systematicity their work involves. What seems special about the experience of scientists who study the past is that apparently, they have to face the past in order to carry out their science. In the case of archaeology, the journey depends on the study of past material remains. Here, important questions emerge: what is involved in this idea of travelling through time? Do scientists of time actually feel they travel through time or is it just a stylistic expression of what they do? Does this experience vary among scientists of time? Is the fact that archaeology deals with material remains important for the experience?

One way, hitherto unexplored, to answer some of these questions is to look carefully at how archaeologists speak about time. Fundamental to this is how the passage of time is understood in stratigraphy. As is well known, the development of stratigraphy, in close relation to geology, is one of the key starting points of the discipline (Harris, 1979). Stratigraphy allowed archaeology to order and correlate its findings in time, by their relative position in the strata. The general principle is, that under normal conditions, when the strata have not been mixed or inverted, earlier findings dating to earlier periods are lower than those dating to later ones. Therefore, in an archaeological excavation, the deeper you go the earlier the things found.

This general understanding of how the passage of time is conceptualized in stratigraphy is systematically manifested in some widespread concepts in Chilean archaeology. One concept of particular relevance for the discipline is profundidad temporal, which has its English correlate in the concept of time depth. ${ }^{3}$ As Bailey suggests, 'for many archaeologists, time depth is what gives archaeology its distinctiveness as an intellectual discipline' (2007:198). ${ }^{4}$ Interestingly Bailey, who uses this concept, along with other related expressions, more than 20 times in his article, is not attempting to analyse it as we are here. He is just suggesting that what makes archaeology unique, compared to other sciences of the past like history, is that archaeology is able to provide a more extended understanding of 
the past that reaches further (earlier) and therefore has a wider scope compared to other approaches. This is clearly expressed by Reid et al., when they suggest that 'within anthropology only archaeology possesses the requisite time depth necessary to the study of long-term cultural change' (1975:866). The word depth qualifies the purchase that archaeology claims on the history of humanity. ${ }^{5}$

The concept of time depth seems to suggest a connection between temporal and spatial properties, namely past and depth. This becomes even clearer when we look at other uses of the concept. There are plenty of instances, both in English and Spanish, in which archaeologists refer to events in time, like the emergence of a technological practice, as having a certain time depth. This connection between time and space corresponds to what has been described as metaphorical mapping in cognitive linguistics (see Lakoff \& Johnson, 1980). According to this theory, abstract domains are systematically mapped onto more concrete domains, generating metaphorical conventions (conceptual metaphors). In this particular case, time is mapped onto space, with the result that temporal and spatial expressions match.

Two ways of conceptualizing time have been systematically described in the literature: Ego Reference Point and Time Reference Point conceptual mappings (Nuñez \& Sweetser, 2006). Both are used in many languages including both Spanish and English. Within Ego Reference Point, two subtypes are included. In the first, called Ego-Moving, we speak of events as fixed landmarks in a linear path in which we are moving, as in the expression 'we are approaching the end of the year'. In the second, called Time-Moving, we speak of times in this linear path as approaching us while we are static, as in the expression 'the end of the year is approaching' (see Figure 1).

What is crucial in Ego Reference Point is that it always refers to an observer (in the two previous examples 'us'). Both in Ego-Moving and in Time-Moving there is a future-in-front and a past-behind because there is an ego involved. Here, future events are in front, present events are co-situated and past events are behind the observer. None of these features occurs in Time Reference Point. Here time has its own internal structure, in which events are in a sequence or succession that does not refer to an observer. For example, in the expression 'Christmas follows thanksgiving', the two events relate to me (the observer) only as I am the one witnessing the relationship between them, but Christmas is not following me and I am not following any of them. As a result, there is no future-in-front and past-behind an ego but only a succession of earlier and later events. This particular mapping has serious implications for temporal concepts like 'before' 
and 'after', which tend to be systematically used in Time Reference Point, as for example in the expressions 'Christmas is after thanksgiving' or 'thanksgiving is before Christmas'. Even though they might be regarded as non-spatial, both before and after have an etymological connection with nautical terminology, in the fore and the aft of a ship. Here the idea of Christmas as being after thanksgiving means not only that it is supposed to occur later in time but also that it is facing the back (aft) of thanksgiving. Conversely, to say that thanksgiving will happen earlier in time is to say that it is in front (facing the fore) of Christmas. In this case, a particular relationship between events emerges, in which each acquires front and back properties depending on the direction of the movement. A similar thing happens to objects moving in a row, like the coaches of a train. We tend to assign front and back properties to the coaches depending on the direction of the movement. As a result, earlier coaches are ahead of later ones. Following the analogy, Christmas, later in time, follows thanksgiving, because the latter is ahead in the queue (see Figure 2).
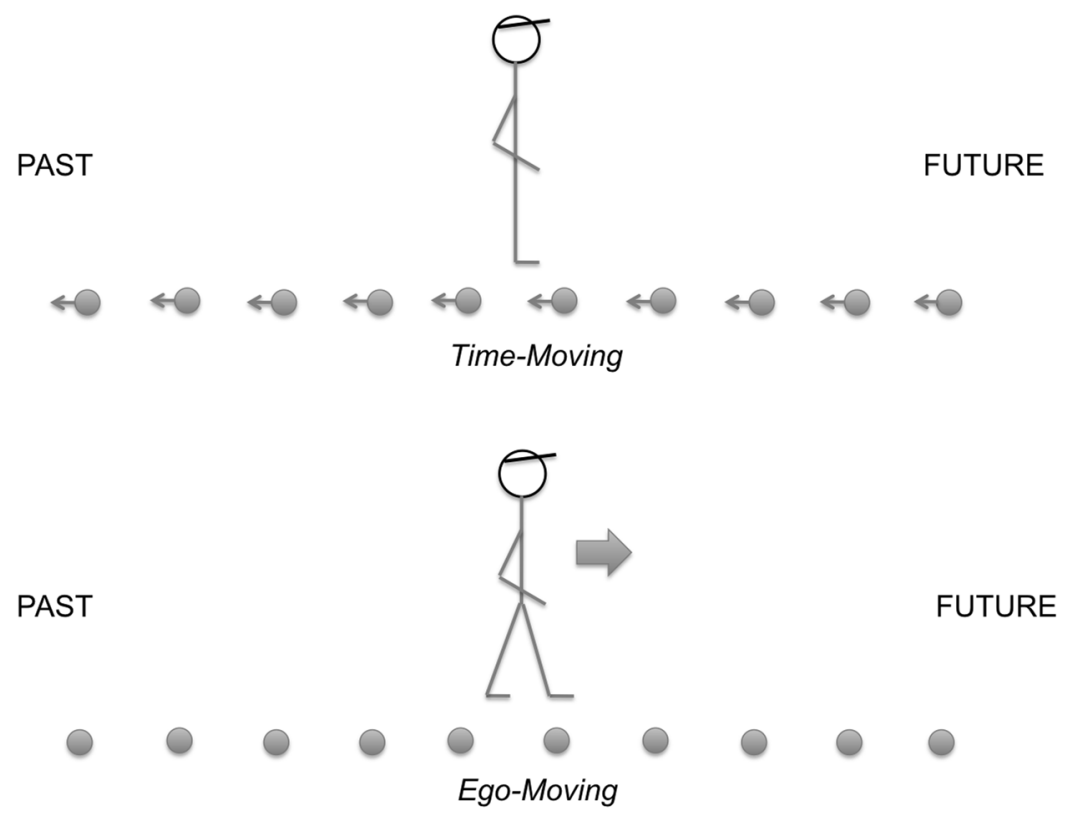

Figure 1: Ego Reference Point. Redrawn from Nuñez and Sweetser, 2006: 406. 


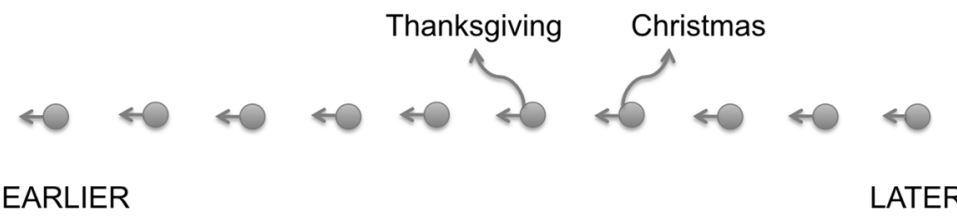

Figure 2: Time Reference Point.

Returning to the question of how archaeologists speak about time, it is possible to find similar expressions to those mentioned above. For example, related to the notion of profundidad temporal in Spanish and time depth in English, archaeologists talk about the experience of going deeper in time. For example in Spanish, Alcina Franch et al., in their study of pre-Colombian navigation in Ecuador, suggest that archaeology allows us to go deeper in time, beyond the arrival of Spaniards ['será la arqueología la que nos permitirá profundizar en el tiempo más allá del citado contacto'] (1987:52, my emphasis). A similar expression in English, can be found in the title of a more recent article of the National Trust for Scotland's Archaeological Bulletin called 'digging deep in time' which talks about ancient excavations at Crathes Castle near Aberdeen (Fraser, 2006:1, my emphasis).

All these examples correspond to the Ego-Moving expression. The striking thing about them is that, compared to the ones described in the literature, they seem to involve the idea of travelling into the past. As we presumed above, this experience does not match the everyday experience people have of feeling time pass behind them as they move forward into the future. When archaeologists talk about their experience of travelling through time they actually mean that they are moving into the past. However, it is still unclear which direction they are moving in when they use these expressions. We do not know whether the word 'deep' refers to the verticality implied in stratigraphy. In fact, we sometimes talk about depths which do not necessarily run downwards, like the 'depth of field [profundidad de campo]' in photography. In this sense, the word depth is ambiguous. Are archaeologists moving backwards when they say that they are travelling into the past, so that they could still have the future in front as in the Ego Reference Point expressions described above? This is the question to which we now turn. 


\section{As we move forward/downward into the past}

To answer the previous question it is necessary to go beyond verbal expressions, as they do not index the location of events in space. One alternative is to look at archaeologists' gestures. Studies in gesture have shown that both speech and gesture are co-produced in time and that gestures usually complement vocal meaning (see McNeill, 1992; Kendon, 1997). At the same time, gestures systematically match metaphorical expressions (Nuñez \& Sweetser, 2006:403). Considering temporal expressions, the study of gesture becomes fundamental for understanding how people think about time. Gestures can index the location of events in space, in this particular case, of where the archaeological 'depth' might be located.

The following transcript is from an interview with a Chilean archaeologist with whom I have been working since 2006, and was recorded in the summer of 2010. When I first met him, while in the process of writing his undergraduate dissertation at a Chilean institution, he had an extensive experience conducting archaeological research. At the time of the interview, he was working on a $\mathrm{PhD}$ in archaeology at an institution in the south of France on indigenous forms of navigation in central Chile. In this exchange, I tell him I came across the concept of profundidad temporal (time depth) while reading his work, and I found some trouble in understanding it. This was a genuine question. It was the first time I talked to this archaeologist about the concept and I first started to ask myself about the particularities of temporal expressions in archaeology while reading his work. Only later on did I realize that it is systematically used by most, if not all, the Chilean archaeologists with whom I worked. After my initial question, the archaeologist spontaneously confirms the starting point of the argument I have been elaborating here. He suggests an identity between 'depth' and 'ancient' (see line 4). Immediately after, he refers to the idea of 'going deeper in time' (see line 6). While saying the word 'deeper' he performs a right-hand gesture in which the movement of the hand matches the trajectory and direction involved in the idea of 'going deeper in time' (see also line 12). Implied in the movement is the idea that the past is not behind anymore, but comes to the fore as archaeologists look downwards to start their journeys. The archaeologist is not moving backwards as he travels into the past. To the contrary, the gesture reveals the experience of moving forward, from the perspective of the archaeologist, and downward into the past, from the perspective of an external observer like me. 


\section{Transcript 1}

Methodological note: The translations of important words are included in parenthesis. Still frames are linked to words in the text using squares that mark the position of relevant gestural strokes. The trajectories of gestures have been summarized using arrows. Contextual descriptions are included in brackets. Relevant parts of the text discussed in the argument are highlighted using italics.

1 C: There is something I wanted to ask you. I have been reading your thesis, which is very interesting and engaging and I found a phrase, a concept I did not understand and took my attention, which is time depth (profundidad temporal).

2 A: [Nods].

3 C: Does it sound familiar to you? You use it several times and $A_{2}$ [another archaeologist from the team] uses it.

4 A: Yes, more depth (profundidad) in time is more ancient (más antiguo).

Ok?

5 C: Ok.

6 A: You go deeper (vas profundizando) in time.

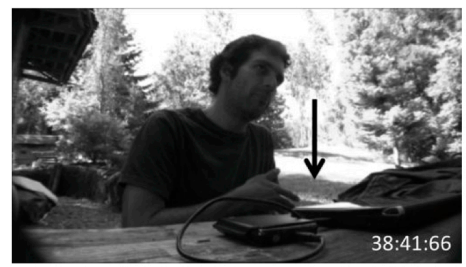

7 A: Less depth in time is more recent (reciente).

8 C: Let me see if I understand you well. Going deeper in time, how is that?

9 A: That you go back (atrás) in time, that is more ancient (más antiguo).

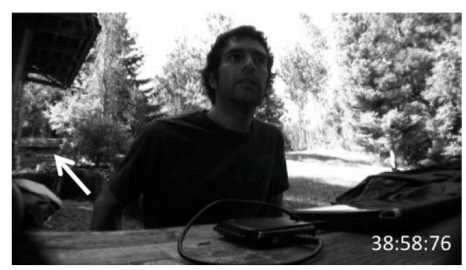

10 A: The concept of depth is used as if... more... [reflecting pause]. It is also the case...[reflecting pause]. You can visualize it as in stratigraphy.

11 A: I don't know... It is supposed that in a properly arranged stratigraphy. 
12 A: what is deeper (más profundo) is more ancient (antiguo)

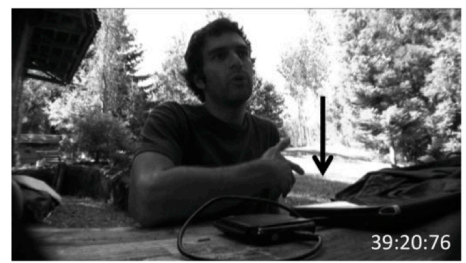

13 C: Ok.

14 A: Most likely. There are cases in which you get mixed stratigraphy or inverted stratigraphy. Then maybe that is the way it is used [reflecting pause]. Because we excavate and the deepest is the oldest, then [reflecting pause]. Like I have never asked myself about the concept, really.

[A few seconds later]

31 C: Mmmm. And?

32 A: Therefore you go deeper in time (vas profundizando en el tiempo)... [reflecting pause] it is used not only in archaeology, like going deeper in time (profundizando en el tiempo). I imagine... [reflecting pause] I don't know. Is it used sometimes?

33 C: In other disciplines?

34 A: In ordinary language?

35 C: I do not know. But for you, is it colloquial?

36 A: Yes.

37 C: Going deeper in time (profundizar en el tiempo)?

38 A: Yes... It is not like high academic language.

39 C: No, but I am not sure whether it is used colloquially. I do not know if everybody would say it.

40 A: No, time depth (profundidad temporal) maybe not, but going deeper (profundizando) in time, sounds more to me.

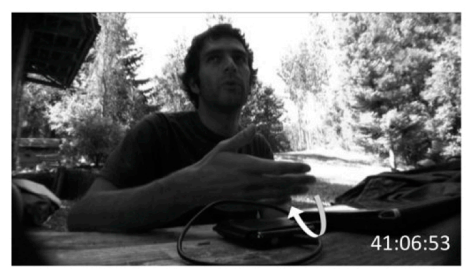

41 C: It sounds more natural to you?

42 A: Yes

This constitutes what we might call a past-in-front type of the Ego Reference Point, which contrasts with the future-in-front expressions described in the literature. In this archaeologists face the past as they travel through time, moving towards what is earlier in time and leaving later events behind. This does not mean that they cannot understand and translate these experiences into the 
terms of the more widespread future-in-front expressions described above. For example, after the archaeologist attempted to explain the concept for the first time, I asked him to clarify again what he meant by the expression 'going deeper in time'. This time instead of using the word 'deeper' he answered using the word 'back', which was accompanied by a backward pointing gesture of the elbow (see line 9). ${ }^{6}$ In the expression 'back in time' the movement is not forwards but backwards, which retains the future-in-front property of the most common Ego-Moving expressions. In this case, the archaeologist seems to have translated the experience of going forward (downward) into the past into a backward movement for me to understand. Using the word 'back' instead of 'deeper', along with this new backward gesture, is decisive here. For by way of contrast, it emphasizes that in the case of the expression 'going deeper in time', depth is downward-oriented and the journey goes from top to bottom, which is perfectly congruent with how stratigraphy works. As archaeologists excavate the soil they move downward into the past. Figure 3 illustrates the point.

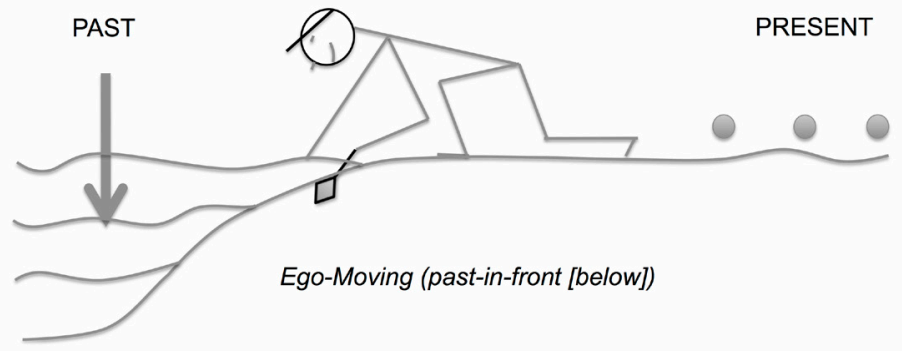

Figure 3: An archaeologist going deeper in time.

Later on the interview, another image of the concept is provided by the archaeologist. This emerged while reflecting on how widespread the expression 'going deeper in time' is even among non-archaeologists, and not as a result of an effort for explaining me the concept. He confessed that the expression, 'going deeper in time' sounds very natural to him and that compared to the concept of profundidad temporal it did not belong to an elevated academic language. He suggested that non-academics use the expression colloquially. While saying the word 'deeper' he performed a gesture different from the ones he had used before. Previously, the hand with all the fingers extended moved downwards as if it were penetrating something. This time he performed a bouncing gesture of the right hand that resembled the movement an archaeologist would make while removing soil with a hand or a trowel, which contrast with how other scientists excavate the past, including for example palaeontologists, who often sculpt solid rock using hammers to reveal fossils (see line 40).

Anuário Antropológico/2013, Brasília, UnB, 2014, v. 39, n. 2: 283-313 
This gesture and the previous ones suggest a connection between different elements in a common domain of experience. In this short sequence, excavation, stratigraphy, and the experience of travelling in time are connected. This occurs by means of a relationship between time and space, reflected in common archaeological temporal expressions. Such ways of speaking are not novel creations but highly conventionalized modes of expression, about which archaeologists do not reflect on a daily basis, as the archaeologist suggests it explicitly (see line 14). Here travelling in time involves the felt experience of moving downward into the past underneath, cutting or removing the soil with a spade, a hand, or a trowel.

\section{Looking at vertical chronologies}

What the analysis above suggests is that archaeologists can locate the past underneath the ground following stratigraphy and the practice of excavation. But are there, in archaeology, Time Reference Point expressions that follow the vertical arrangement of strata? Several concepts in archaeology, and other related sciences of time that rely on stratigraphy, suggest verticality in chronological thinking. For example, some historical periods are divided using vertical terms, like Lower and Upper Palaeolithic (Lucas, 2005). This corresponds to how most geological charts are displayed, with earlier events at the bottom and later events at the top. Such illustrations contrast with other ways of visualizing chronologies, like historical timelines, where time runs horizontally from left to right. This corresponds with the way reading and writing - the most common activities historians engage in as they approach the past - unfold in Romance and Germanic languages. ${ }^{7}$

One concept in vertical chronology, particularly popular in Chilean archaeology, is 'subactual'. Even though it is possible to find examples of this concept in Anglo-Saxon archaeology, its translation is ambiguous since 'actual' in English does not mean current as in Spanish but real or true. It is particularly interesting, however, since it contrasts with other concepts we have mentioned already, particularly 'time depth'. To simplify things I will translate subactual as 'sub-present'. Asking the leading Chilean archaeologist from the team about the meaning of the concept, a few weeks after the previous interview was conducted, he gave the following explanation:

Sub-present (subactual) is something that is underneath the present (bajo lo actual) in terms of temporal depth (profundidad temporal). It is something that is not 
contemporary, [something] more ancient (antiguo) but does not acquire the category of archaeological (my emphasis).

In this case the archaeologist had his hands in his pockets so there is no point in showing pictures. However, speech is sufficient to indicate the verticality of this chronological concept. As the prefix 'sub' suggests, sub-present is something beneath the present, therefore earlier but not early enough to be of archaeological interest. It is important to mention that the most recent material remains are not protected. For example in Chile, by law anything aged 50 years or older acquires archaeological status, becoming a national monument. However, beyond this abstract and static definition in the law, among archaeologists this chronological category, like many others, is continually debated. The number of years that define sub-present varies considerably among researchers and is strictly related to the particularities of their research, its current focus and interests. However, each time an object is assigned to this category, it is against a periodization in which present materials are above at the surface level and archaeological materials are slightly below, deeper in time. Applying this category presupposes a vertical chronology.

Another concept that suggests a vertical chronology is the notion of 'temporal column (columna temporal)'. Even though less popular, it is currently used in Chilean archaeology. Compared to the previous one, this concept is ambiguous because it is not clear in which direction the chronology runs (from top to bottom or the other way around). The following interview conducted again in 2010 with another archaeologists from the team disambiguates the concept and shows that sometimes archaeologists use Time Reference expressions like after and before in a vertical way when referring to the relationship between events in time. As in the previous interviews I started by asking the archaeologist about the meaning of the concept. He suggested that temporal column refers to a periodization that is possible to find in what he called 'the general line of development of culture'. Two types of gestures were performed, and repeated several times during the interview. First, in line 2, along the word 'periodization', he marked with both hands the beginning and end of the sequence. Second, in line 4, along the phrase 'general line of development of cultures', he performed twice a gesture that drew a vertical line with the right hand, starting at the bottom from the left hand near the stomach. ${ }^{8}$ Then, as he went back to the idea of temporal column in line 6 , he repeated the first gesture marking the beginning and end of the periodization with both hands. 


\section{Transcript 2}

1 C: So, what is the meaning of temporal column (columna temporal)?

$2 \mathrm{~N}$ : It is a periodization (periodificación).

3 C: $0 \mathrm{k}$.

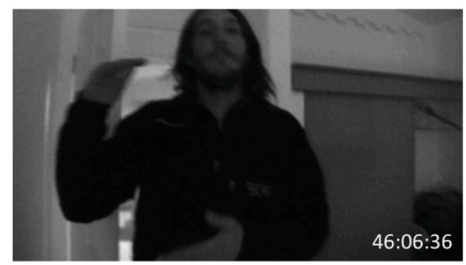

$4 \mathrm{~N}$ : that we are going to find, for example, in this like general line of development (línea del desarrollo) [with this word the last gesture is repeated] of cultures.

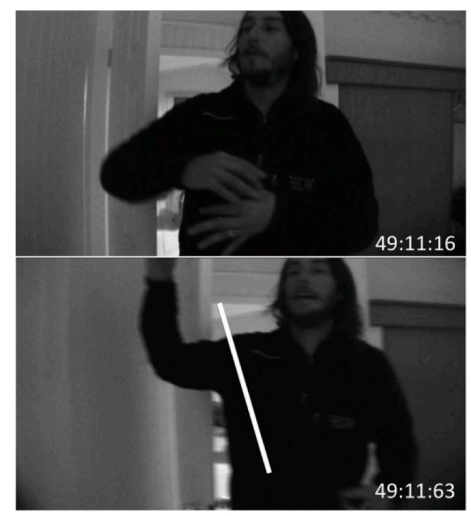

5 For example, here in Chile, the periods in which history has been classified [with this word the last gesture is repeated] have a time [with this word the last gesture is repeated].

6 This is what we might call temporal column.

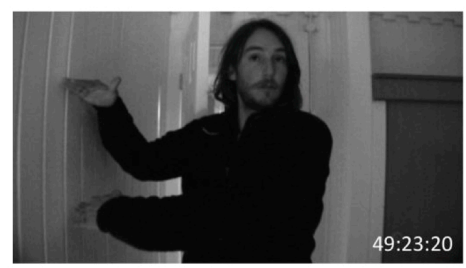


7 And sometimes it is the case of what we were recently talking about, of what for example it is said of the archaic period of the population from the coast, for example here in the Little North [Norte Chico, a geographic subdivision in Chile]. That archaic period (período arcaico) [with this word the last gesture is repeated] covers a certain number of years (años) [with this word the last gesture is repeated]

that can go from 3000 before (antes) Christ to 900 or 500 after Christ. So therefore, it is a demarcation for delimiting within this general line, what is covered by each period.
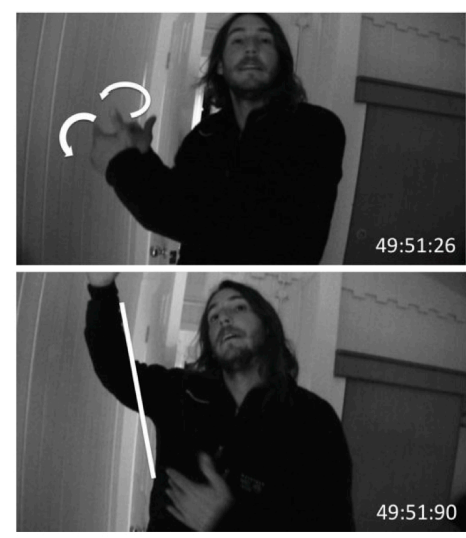

All these gestures once again suggest verticality in how the archaeologist conceptualizes the passage of time. However, it is still unclear whether earlier times are at the bottom of the column and later times at the top. This only became clear in line 8, when he referred to the extension of the Archaic Period in Chile, which 'can go from 3000 before Christ to 900 or 500 after Christ'. In so doing, he again marked the beginning of the period with a spinning movement of both hands next to the right shoulder and an upward movement of the right hand when he moved to the latest time of the period. This suggests that earlier events are below later ones, and conversely, that later events are on top of earlier ones, like the birth of Christ, which is after (and on top of) the beginning of the period and before (or below) its end.

\section{Comparing archaeological time across the globe. Towards an understanding of the emergence of concepts}

Even though knowledge in archaeology is nowadays globally distributed, as the conceptual similarities between archaeology carried out in languages like Spanish and English suggest, there are places in which the verticality of time takes different shapes. As Barnes (1990) shows, in a remarkable work on archaeologists' chronological thinking in Japan, the passage of time can be understood as moving in the opposite direction. Even though Japanese archaeologists 
conceptualize chronologies vertically, they run from top to bottom. This is partially due to the slow introduction of stratigraphy in archaeology and the prevailing influence of traditional chronologies on the interpretation of the archaeological record. Even though excavation had long been practised, stratigraphy was only introduced in Japan in the twentieth century. Most stratigraphic concepts were appropriated following a traditional chronology concerning the origin of the Japanese imperial family. Antiquarians and early archaeologists put much of their effort into confirming these ancient scriptures. Still extant today, this chronology comes from two traditional court chronicles from the $8^{\text {th }}$ century, the Kojiki and the Nihon Shoki. According to the latter, history is divided into two eras: the Age of the Gods and the successive Imperial Ages. The myth suggests a continuum between the two ages, from one stage above (heaven) to another stage below (earth). Such chronology left no room for an unrecorded prehistory and it took considerable time for archaeologists to conceive of such a period. As a result, chronology was conceptualized as a movement from top to bottom rather than the other way around. As Barnes suggests, the influence of genealogical chronologies is still present in the way Japanese archaeologists speak about time. For them to go back in time is 'to go up in time' (sakanoboru) and conversely to move forward in time is 'to come down in time' (kudaru). According to Barnes such conceptualization has parallels in China and Korea, which again match a vertical chronology of what we can call an early-up kind rather than the late-up we have described above. Figure 4 illustrates both chronologies. Whether late-up expressions are consistent with the ways Japanese archaeologists gesture is again an open question. But following Barnes (1990:939), it is evident that 'archaeology is not a single, unified discipline', with unified ways of conceptualizing time. ${ }^{9}$ Conceptualization does not emerge in a vacuum but in the crucible of already established disciplinary practices that have their own histories and vary between scientists of time and within the same science across the globe. ${ }^{10}$ But how do temporal concepts emerge? 


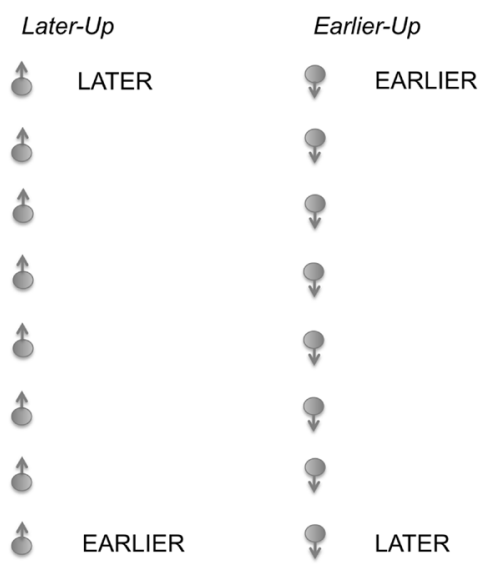

Figure 4: Later-up vs. earlier-up.

In most of the conversations about time expressions I had with archaeologists, it was clear that they used these concepts without reflecting on their vertical properties. They are highly conventionalized rather than improvised on the spot. Even though the archaeologists usually arrived at a link between verticality in soil deposition and verticality in time, as I invited them to reflect with me on their concepts, they never fully realized their systematic relation. They often said that this was the first time they had thought about these concepts and that their use extended colloquially beyond the geosciences. These ideas were mentioned explicitly during the first interview shown above. After linking the concept of 'temporal depth' with stratigraphy, the archaeologist realized he had never thought about the concept before, even though he had been using it for a long time (see line 14), and suggested that the expression 'going deeper in time' belongs to a wider non-academic language (line 32 onwards).

Interestingly, every time I suggested the systematic verticality of their concepts, the archaeologists would agree and look surprised as if they had discovered something of which they had not previously been aware. The systematic verticality of their temporal concepts is not consciously thematized unless they pay attention to it. They do not analyse their concepts on a daily basis as I have been doing here. They just use them. ${ }^{11}$ This is consistent with the way consciousness unfolds. Our experience of the world is selective. We attend to some things while others remain in the background. The latter is the case not only for perception but also for the way our language is constituted. When we use language we do not think of the meaning of each word before using it. And each time we reflect on a word our entire world is presupposed. We did not decide on our mother tongue. To the contrary, we find ourselves speaking it. And we become experts in using it by not reflecting on the meaning of every single Anuário Antropológico/2013, Brasília, UnB, 2014, v. 39, n. 2: 283-313 
word. Otherwise, it would take us forever to say something, if we ever managed to say anything. Words emerge while we remain focussed on the general aim a conversation is trying to fulfil, within the particular tension of the moment. Words and gestures are subsidiary to this general path even though they are the soil that makes it possible. Meaning emerges in the attempt to move in a particular direction. The path is not a collage but a continuous movement. As a result, the systematic relationship of our concepts remains in a tacit dimension. Following Polanyi (1983:10), we could say that they stay in the proximal aspect of our consciousness rather than the distal focus. This does not mean that we are not the users of these words. It is like with peripheral vision, a form of vision that works only so long as we are not paying attention to it. In this a dynamic relationship emerges. Each time our attention moves, what was previously our focus fades into the background and something of the periphery comes to the fore. In this sense peripheral vision is crucial to visual perception, as it grounds the movement of attention across the visual field.

This experience is probably close not only to how archaeologists use their concepts but also to how they create them. This insight was shared by one anthropologist who was an active member of the Chilean team of archaeologists I worked with. It is worth noting that in this group, archaeologists and anthropologists worked together systematically not only excavating sites but also carrying out ethno-archaeology. There were no rigid disciplinary boundaries between them in terms of the type of job each carried out, of the kind that British archaeologists and anthropologists have long been resisting (see, e.g., Gosden, 1999; Yarrow \& Garrow, 2010). To the contrary, they were understood as two paths in the same endeavour. This anthropologist, who worked among other things in a museum looking at the relationship of the institution with the public, was developing a project that attempted to bring archaeology closer to young members of the community. With a colleague, he developed a concept that was intended to make learning about oral traditions and material culture more accessible. They called the concept Stratigraphy of Memory. The concept was illustrated in a diagram, according to which the history of a community was conceived to be deposited vertically and remembering was a downward movement (Alvarez \& Godoy, 2001:34).

This notion is fully congruent with the vertical time expressions described above. In this case however, we are not dealing with a conventionalized expression in which the relationship between different conceptual domains remains in the background. The authors are making explicit analogical connections between the domains of stratigraphy and memory. However, as a 'novel' concept 
it has the potential to extend beyond its authors and the young students who learned local history by using it. In that sense, the way this metaphor emerges can shed light on how conventional metaphors are constituted. Asking the anthropologist how he conceived the idea, he came up with the following, very spontaneous, answer: 'I do not know... things that occur to you' (no se, cosas que a uno se le ocurren, my emphasis)

Particularly interesting in his answer was the tone he used. It was as if he was not responsible for the concept. Even though, he knew what he meant by it, it seemed that the particular metaphor he picketed up was not his conscious decision. It was as if he had arrived at it by chance. Interestingly, the word ocurren (like the English word 'occur'), used here to refer to something that comes to your mind, has its origin in the idea of something that happens. It is relevant to say that these two usages have a particular grammatical difference in Spanish. Things that happen to you (cosas que a uno le ocurren) and things that come to your mind (cosas que a uno se le occurren) are differentiated in Spanish by the reflexive se, which refers to someone. However, the close connection between these two uses of the word 'occur' nicely captures the way in which the anthropologist referred spontaneously to the emergence of his concept. There was a subtle sense in which the concept he came up with had also come to him, without any conscious decision on his part. Even though he, and his colleague, coined the concept they did not set all the conditions for it to emerge. This is one of the most critical aspects of the emergence of concepts. They are happenings that do and yet do not depend on someone. Following Bakhtin, 'any speaker is himself a respondent to a greater or lesser degree. He is not after all the first speaker, the one who disturbs the eternal silence of the universe' (2006:101). Thus concepts are neither baptismal creations nor mere historical imposition. They are what we can call agentive happenings.

It is important to mention that even though this concept emerged as new, as it was applied in a new context and for a very particular purpose, similar ideas can be traced downward (or backwards) in time (see Thomas, 2004; Olivier, 2011). Freud (1955:298-9) was probably the first to suggest an analogy between memory and stratigraphy. His work influenced many prominent anthropologists, including several of the students of Franz Boas. Through them, and many others authors from different parts of the world, the analogy spread within anthropology. Later on, it was applied to other dimensions of existence, such as meaning and symbolism (see, e.g., Sapir, 1985; Turner, 1967; Levi-Strauss, 1973) and the history of knowledge (Foucault, 1972). After so many years a degree of conventionalization has been instituted. Most psychoanalysts would Anuário Antropológico/2013, Brasília, UnB, 2014, v. 39, n. 2: 283-313 
be happy to suggest that their approach, compared to others within psychology, digs deeper into the patient's history. This is why psychoanalysis was originally defined by its own proponents as deep psychology. Probably, like archaeologists, psychoanalysts do not have in mind all historical background that surrounds these expressions when they use them.

The idea of agentive happening also summarizes how these concepts are learned in the first place, in that as the analysis presented here suggests, these happenings are not just the product of a socially constructed history but depend on how others have perceptually engaged with the material world through feeling and moving. Accordingly, as agentive happenings concepts are, at the same time, neither constructed nor discovered, but grow as archaeologists learn to ecologically appropriate their environments through practice. As the archaeologist on the second transcript told me once, after talking about some of the temporal expressions we have been analysing here, at the beginning it took him a long time 'to be able to land (aterrizar) these concepts' (my emphasis). Looking backwards he realized that in the first years of his undergraduate he did not fully grasp them. Even though, they made apparent sense they did not meant what they mean now. And among his lecturers some had the ability to land these concepts while others left them flying way above without being able to catch them. Interestingly, for him learning those concepts was not the result of a simple conscious decision. Learning the concepts of his discipline was part of a process that took him a long time and depended on being able to ground them. Their meaning was again both something he arrived at and something that happened to him, which probably emerged as he engaged in an archaeological community of practice that often pays attention to landscapes, where things are supposed to fall to the ground and accumulate stratigraphically through time as a result of gravity.

Regarding this analysis of time in archaeology, the same goes for me as I engage in this conceptual endeavour. Having participated in different archaeological fieldworks, sharing with archaeologists some mayor practical concerns during survey and excavation helps me to make sense of archaeological concepts. Each time I reflect on them, the felt experience of spending hours making sections even, excavating test pits, following differences in soil, walking through the landscape, reading and interacting with archaeologists is presupposed. I would have never made sense of them without first sharing with archaeologists in contexts of practice the vast background of their discipline across the gravitational properties of the landscape. If I had done it seated on my desk probably these concepts would mean something different now. 


\section{Conclusion: Some implications for time in archaeology and time concepts in general}

I have shown how archaeologists working in Germanic and Romance languages like English and Spanish tend to conceptualize time vertically. This verticality matches the way stratigraphy works and the practice of moving downward in an excavation. Even though archaeologists realize this relation, they do not reflect on a daily basis on how their concepts are constituted. As agentive happenings, concepts are partially occluded. This is consistent with the partial awareness of the relation between time concepts and corporeal movement that has traditionally existed within archaeological theory (also, Simonetti, 2013). If there is a circular relation between practice and conceptualization, so that practice depends on time concepts and concepts of time depend on practice, then archaeology needs to pay attention to this relationship 'as if' for the first time, having the directionality of movement always on sight. For as should now be clear, and as most of our temporal expressions confirm, time is never divorced from the way we move in the environment, which applies both to the experience of moving through time and the measurement and representation of chronological trajectories. Our concepts are continuous and co-constitutive with how we corporeally appropriate our environments through feeling and moving.

Returning to the time metaphors described above and the complexity of their trajectories, these have not so far as I know, been linguistically described before. There is widespread belief in cognitive linguistics that in Indo-European languages the future-in-front version of the Ego Reference Point is universal across cultures. Work in linguistic anthropology, however, has suggested that in non-Indo-European languages like Malagasy, in the Austronesian languages (see Dahl, 1995), and in Aymara, a Jaqui language (see Nuñez \& Sweetser, 2006), time can be inverted, having a future behind rather than in front. Beyond such comparisons, I have shown that there is more variability within Indo-European languages than has previously been thought. Ultimately, there has never been anything like a 'Standard Average European' language as Whorf (1959:138) once suggested.

The lack of attention to variability in western time concepts is not surprising. Comparisons have been driven by a fascination with exotic languages. Here, a particular understanding of cultures and language plays a crucial role. Cultures are conceived as bounded entities and languages as essential and fixed properties of cultures. As a result, variability is expected between languages and not within them. Notions like 'inter-cultural' and 'cross-cultural', used in some of the comparative studies mentioned above clearly show this general assumption. 
For example, the 'inter' in interculturalism, presupposes an understanding of cultures as having internal as opposed to external properties, as do the opposite concept of intra-culturalism (Ingold, 1993a). Interestingly, the same goes for the type of knowledge we are analysing in this article. The term interdisciplinarity presupposes an understanding of disciplines as bounded entities.

Accordingly, it is impossible to pin down the stratigraphic understanding of time within the academic culture as it has influenced many areas outside geology and archaeology, such as psychology, anthropology, and philosophy, among others. Such influence has also spread into many aspects of the non-academic world. However, it is worth noting that like any other understanding of time, the vertical one in archaeology belongs to a particular history of practices that makes its conceptualization unique compared to other academic and non-academic ways of conceptualizing time. This clearly does not prevent non-archaeologists understanding and using these concepts and certainly does not mean archaeologists are not familiar with other non-vertical ways of conceptualizing time, such as the common horizontal chronologies used by historians. In fact a confluence of multiple ways of understanding time is expected in science, especially among those who engage in collaborative forms of research.

Regarding this last point, the verticality of time in archaeology does not constitute a static phenomenon as it has been continuously reworked as archaeologists collaborate with scientists from other disciplines. One example is the development of the landscape approach that in recent years has challenged the emphasis on excavation, with a corresponding emphasis on the use of survey (see, e.g., Tilley, 1994; Bradley, 2003). As I have argued elsewhere, this has invited archaeology to take a distance from disciplines that emphasize a vertical appropriation of the landscape (e.g. geology) while at the same time approaching disciplines that emphasis horizontality (e.g., geography) (Simonetti, 2013, 2014). In this horizontality, expressions that follow an Ego Reference Point of the type future-in-front are more appropriate, as they follow the experience of walking on the surface of the earth (see, e.g., Ingold, 1993b). ${ }^{12}$

Going back to how language has been understood, more specifically, in Conceptual Mapping Theory (CMT), the evidence presented here reveals important differences. Lakoff and Johnson $(1980,1999)$ have systematically uncovered the metaphorical properties of language. In so doing, they have shown how what we have traditionally conceived as abstract domains are grounded in our everyday experience of bodies that move in the environment. Unsurprisingly, however, the tendency has been towards conceptualizing the body rather than embodying the language (Cornejo, 2007). In CMT, the metaphorical mapping is always 
unidirectional, from corporeal domains on the one side to abstract cognitive domains on the other. In addition, the metaphorical integration of conceptual domains such as time and space is supposed to occur at an abstract conceptual level. This is what leads Evans to argue that 'the basis of temporal experience is "between the ears" rather than "between the stars"; the provenance of time is internal rather than external' (2007:735). Within cognitive linguistics time is considered to be an unperceivable abstraction and not a felt experience, therefore partially separate and discontinuous from movement in space (see, e.g., Boroditsky and Gaby, 2010:1635). This mirrors the enclosed understanding of culture. Cognition here is an internal process, bound by the skin and divorced from our sentient experience of appropriating our environments in movement.

Yet, following Sheets-Johnstone (1999:359), as entities fundamentally constituted in movement, mainly through the growth of a kinaesthetic sense, we do not experience ourselves as packaged as the notion of embodiment, commonly used in cognitive linguistics, invite us to believe. We are just there in the open (also Heidegger, 1962). In this openness, constituted through the development of a capacity to feel in movement, the division between an inside and an outside is not at issue. We will never know where conceptualization begins and realreality ends, as we have never been within or absent from either of them. Following this argument, variations are not attributable to the different concepts that people hold in their minds. To the contrary, language survives only in our expressions, which are continually forming as we dwell in the world (Ingold, 2000:404). The crucial difference between CMT and the approach I am suggesting here lies in my rejection of the widespread understanding of language as a self-contained variable in a causal process in which other variables, like perception or the body, are involved. I rather suggest thinking language in life. In this perspective the well-established idea, within cognitive linguistics, of the metaphorical construal of time, makes no sense. Following Jackson (1983:328-9), falling in a moral sense and falling to the ground are connected not as a result of an abstract conceptual integration but because there is an existential continuity between the two experiences. As you fall morally you can also feel your body falling to the ground. Concepts are neither constructions 'inside' the head nor discoveries 'out there'. They are what we might call sentient conceptualizations, in that concepts emerge as we go together through life corporeally appropriating our gravitational environments, through feeling in movement, in the footsteps of our predecessor.

It is worth noting that this understanding of conceptualization challenges the initial emphasis on construction within the sociology of science (see e.g. Anuário Antropológico/2013, Brasília, UnB, 2014, v. 39, n. 2: 283-313 
Knorr-Cetina, 1983; Latour \& Woolgar, 1986; see also Latour, 1993, 1999 for a significant departure within the field), as well as the many comparative understandings of ontological differences (see e.g. Descola, 1996:82) and the many analysis of knowledge in archaeology that rest on this idea (see e.g., Shanks \& Tilley, 1987:135; Meskell \& Preucel, 2004:16; Olivier, 2004:212). Like the vertical understanding of time described here, this emphasis on construction has serious implications for how cultural knowledge is understood in disciplines such as anthropology and archaeology. Forgetting them, necessarily involves the risk of unnecessarily projecting a temporal understanding into other cultures, denying them coevalness (Fabian, 1983; also Simonetti, 2013).

Returning to the archaeologists, the idea of travelling downward into the past is foreign to many people who speak the 'same' language. In fact not everyone would say something like going deeper in time, even though the meaning of the expression might come up intuitively, as we all have the experience of turning around and looking downwards. Imagine pre-school children and all the people who are not necessarily familiar with archaeology or any other systematic form of interest in the past. Compared to them archaeologists face a past that is underneath, and as they attempt to understand it they feel that they move forward into it. This presents a paradox in relation to the more common futurein-front understanding of time, equivalent to the one epitomised in the famous 80 's movie 'Back to the Future'. The paradox was materialized in the way the letters of the title pointed back and forth in both directions. ${ }^{13}$ Compared to that title, archaeologists seem to be doing it vertically. They travel forward but downward into the past, while time passes for them as they remove past layers of soil. And as they do so, their knowledge starts to emerge from the deep. In a way, archaeologists do not build their conceptual edifices. They rather excavate them.

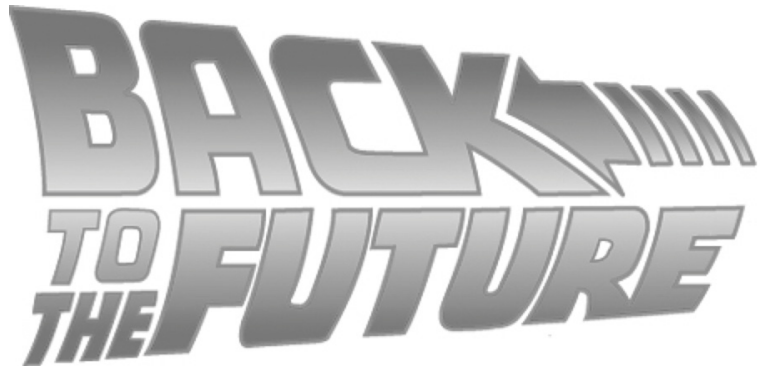

Figure 5 - Traveling forward but backwards in time. Logo of the movie 'Back to the Future'. Courtesy of Universal Studios Licensing LLC. 


\section{Acknowledgements}

I would like to thank the many archaeologists and anthropologists with whom I worked in Chile. This article would have been impossible without their support. Also, I would like to thank Tim Ingold, Alex King, Jeff Oliver, Gordon Noble, Chris Gosden, Cesar Giraldo Herrera, Rolando Sillas and Miriam Rabelo for their very generous comments on earlier version of this article, one of which was presented in 2014 at a short course organized by Carlos Sautchuk from the Programa de Pós-Graduação em Antropologia Social at the Universidade de Brasília. I am grateful to Carlos and to all those who attend the course and gave me feedback. This work counted with the support of two PhD studentships awarded by the Chilean National Commission of Scientific and Technological Research (CONICYT) and the College of Arts and Social Sciences, University of Aberdeen. It was also supported by the project Fondecyt $\mathrm{N}^{\circ} 1060216$, in charge of Leonor Adán. My sincere thanks to her and her team. Also, I would like to thank Universal Studios for allowing me to reproduce figure 5 included in this article. Finally, I am grateful to the Royal Anthropological Institute for awarding an earlier version of this article the Arthur Maurice Hocart Essay Prize in 2010.

Recebido em 08 de agosto de 2014 Aceito em 26 de setembro de 2014

Cristián Simonetti has conducted fieldwork ewith land and underwater archaeologists in Chile and Scotland, and with glaciologists in Greenland. His research focuses on perception and communication, the role of corporeal movement in processes of enskilment and the use of technology. It concentrates especially on the relationship between experience and conceptualization, particularly on how scientists studying the past understand time and space. He is currently working on scientific understandings of time in the interdisciplinary study of climate change. E-mail: cesimonetti@abdn.ac.uk 


\section{Notes}

1. The argument presented here rests on an extensive analysis of archaeological practices and their forms of knowledge productions, which I am unable to describe here in detail, as the analysis of time expressions and gestures is the main concern of this paper. This analysis is based on long term ethnographic research, carried out with archaeologists in Chile and Scotland (see Simonetti, 2012, 2014), and concentrates on a detailed descriptions of a selected number of interviews conducted in the summer of 2010 with members of a Chilean team of land and underwater archaeologists with whom I have been collaborating since 2006. The temporal expressions analysed here are used by most, if not all, the many archaeologists with whom I worked in Chile, and are part of much wider academic culture that reaches into most Indo-European languages, including English, French and Portuguese.

2. In recent years, several authors have started to question this focus by suggesting that archaeology is not only about the past but also about the present (see, e.g., Yarrow \& Garrow, 2010). Even though this discussion attempts to confront the excessive focus on an objective and dead past by paying attention to its connection with the present and the future, what these criticisms cannot deny is that archaeology will never stop dealing with time if it wants to remain the discipline it is. Archaeology, in a fundamental sense, is condemned to reflect about time, as long as it tries to understand human habitation of the world, in the company of things and other species, by looking at past remains.

3. Although the goal here is to point out some commonalities, it is worth noting that these expressions belong to different academic communities. Although analogous in their temporal directionality, these 'depth' can mean different things depending on the context. According to Trigger (1984) archaeologists can produce alternative archaeologies, depending on their often subtle political goals and whether they are studying 'their own', as opposed to 'someone else's, past. Such differences are beyond the goals of this article.

4. The concept of time depth is also common in geology. For example, Gould (1987), in his study of the origin of geological time, suggests that the discovery of 'deep time' changed our understanding of history forever. Like many archaeologists, Gould starts his analysis of deep time by paying attention to abstract dichotomies that do not do full justice to how geologists conceptualize time, namely the distinction between time's arrow and time's circle.

5. These are not essential properties but relative to each particular comparison. It may well be that a different answer would be given to the question about the difference between history and archaeology, if the focus were on historical archaeology rather than prehistoric archaeology. And again, if the word 'depth' were used, it would probably mean something different. 
6. The expressions 'back in time', 'deeper in time' and 'traveling in time' use 'in' ('en', in Spanish) to suggest an idea of movement within an enclosed path. These expressions correspond to a sub-sense of what Evans (2007:740) describes as movement sense, in his analysis of the uses of the word 'time'. They involve an ego-centered motion which is non-terminal, as it does not end with an event (such as 'the end of the year'), and time behaves as a count noun, before which no article is used. However in Spanish, the definite article 'el' is added after 'in' (en). Regarding the word past, the expression 'traveling into the past', adds a 'to', which suggests the idea of movement into the interior of a container.

7. Studies in cognitive linguistics show that the direction in which languages are written influences the direction of chronological thinking (Fuhrman and Boroditsky, 2010; Boroditsky et al., 2010). Whether this corresponds with the way time expressions are conveyed verbally and gesturally in those languages remains an open question.

8. It is interesting to note how the direction of time is represented in this chronology, and presumably in most narrative descriptions of the past, from earlier events to later ones. The etymology of most Time Reference terms suggests that events move the other way around. In the latter case we are talking about events following each other while in the former about the trajectory of time from beginning to end. The direction of the sequence of events does not match the trajectory of time in chronological thinking.

9. Within Anglophone archaeology there seem to be other unexplored variations. For example, Trigger (2006:41), contents that British archaeologists tend to put earlier times at the top of their vertical chronologies whereas American archaeologists put them at the bottom. This, he suggests, is because the latter favours evolutionism. Whether this is actually the case remains an open question.

10. Going beyond Barnes' analysis it is also important to mention that Japanese, like Mandarin, is written from top to bottom, which has probably influenced the way archaeologists conceptualized chronologies in Japan (see Boroditsky et al., 2010).

11. This conceptual occlusion is not exclusive of Chilean archaeologists. In talking to archaeologists using analogous concepts in an Anglophone context, while conducting fieldwork among archaeologists in Scotland, they also tend to look surprised, when I invite them to reflect on the background of their concepts.

12. A slightly more informed and explicit horizontalization can be observed in Harrison's (2011) recent invitation to develop an archaeology in and of the present limited by what is visible at the surface (see also Simonetti, 2014).

13. This paradox is not completely foreign to non-scientists. For example, the back-up system time machine, recently lunched by Apple, allows users to move back in time to see their old desktops. You have the experience of moving forward in time as the most recent desktops go by. Interestingly, the arrow you have to press to move forward to earlier desktops is called the 'back arrow'. Here you are moving back-forward into the past. 


\section{References}

ALCINA FRANCH, José et al. 1987. "Navegación precolombina: el caso del litoral pacífiCO: evidencias e hipótesis”. Revista Española de Antropología Americana, XVII: 35-73.

ALVAREZ, Rodrigo \& GODOY, Marcelo. 2001. "Experiencias rurales de educación patrimonial en la décima region”. Revista Austral de Ciencias Sociales, 5:29-38.

BAKHTIN, Mikhail. 2006. “The Problem of Speech Genres”. In: Adam Jaworski \& Nikolas Coupland (eds.). The Discourse Reader. Oxon: Routledge. pp. 98-107.

BAILEY, Geoff. 2007. "Time Perspectives, Palimpsests and the Archaeology of Time". Journal of Anthropological Archaeology, 26:198-223.

BARNES, Gina. 1990. “The 'Idea of Prehistory’ in Japan”. Antiquity, 64:929-940.

BORODITSKY, Lera \& GABY, Alice. 2010. "Remembrances of Times East: Absolute Spatial Representation of Time in an Aboriginal Australian Community”. Psychological Science, 21(11):1635-1639.

BORODITSKY, Lera; Fuhrman, Orly \& McCormick, Kelly. 2010. “Do English and Mandarin Speakers Think about Time Differently?” Cognition, 118(1):123-129.

Bradley, Richard 2003. "Seeing Things: Perception, Experience and the Constraints of Excavation”. Journal of Social Archaeology, 3(2):151-168.

Cornejo, Carlos. 2007. "Conceptualizing Metaphors versus Embodying the Language”. Culture \& Psychology, 13(4):533-546.

Dahl, Øyvind. 1995. "When the Future Comes from Behind: Malagasy and other Time Concepts and Some Consequences for Communication”. International Journal of Intercultural Relations, 19(2):197-209.

Descola, Philippe. 1996. "Constructing Natures: Symbolic Ecology and Social Practice”. In: Philippe Descolas and Gisli Pálsson (eds.). Nature and Society: Anthropological Perspectives. London: Routledge. pp. 82-102.

Edgeworth, Matt. 2003. Acts of Discovery: an Ethnography of Archaeological Practice. Oxford: Archaeopress.

2006. Ethnographies of Archaeological Practice: Cultural Encounters, Material Transformations. Lanham, MD: Altamira Press. 
Evans, Vyvyan. 2007. "How We Conceptualize Time: Language, Meaning and Temporal Cognition”. In: Vyvyan Evans, Benjamin K. Berger and Jörg Zinken (eds.). The Cognitive Linguistics Reader. London: Equinox. pp. 733-765.

Fabian, Johannes. 1983. Time and the Other. New York: Columbia University Press.

Foucault, Michel. 1972. The Archaeology of Knowledge. London: Tavistock.

Fraser, S. 2006. "Digging Deep in Time: Crathes Goes Back 10,000 Years". NTS Archaeological Bulleting, 25:1.

Freud, Sigmund. 1955. "Studies in Hysteria (1893-1895)”. In: . The Standard Edition of the Complete Psychological Works of Sigmund Freud, vol. II (trans. J. Strachey). London: Hogarth Press.

Fuhrman, Orly \& Boroditsky, Lera. 2010. Cross-cultural Differences in Mental Representations of Time: Evidence from Implicit non-Linguistic Task. Cognitive Science, 34(8):1430-1451.

Gell, Alfred. 1992. The Anthropology of Time. Oxford: Berg.

Goodwin, Charles. 1994. "Professional Vision”. American Anthropologist, 96(3):606-633.

GOULD, Stephen J. 1987. Time's Arrow, Time's Cycle: Myth and Metaphor in the Discovery of Geological Time. Cambridge, MA: Harvard University Press.

Gosden, Chris. 1994. Social Being and Time. Oxford: Blackwell. 1999. Archaeology and Anthropology: a Changing Relationship. London: Routledge.

Harris, Edward C. 1979. Principles of Archaeological Stratigraphy. London: Academic Press. Harrison, Rodney. 2011. "Surfaces Assemblages: Towards an Archaeology in and of the Present”. Archaeological Dialogues, 18(2):141-161.

Heidegger, Martin. 1962. Being and Time. Malden, MA: Blackwell.

Ingold, Tim. 1993a. "The Art of Translation in a Continuous World”. In: Gísli Pálsson (ed.). Beyond Boundaries: Understanding, Translation and Anthropological Discourse. Oxford: Berg. pp. 210-230.

1993b. "The Temporality of the Landscape". World Archaeology, 25(2):152-174. 2000. The Perception of the Environment: Essays in Livelihood, Dwelling and Skill.

London: Routledge. 
Jackson, Michael. 1983. "Knowledge of the Body". Man, 18(2):327-345.

Karlsson, Håkan. 2001. It’s about Time: the Concept of Time in Archaeology. Göteborg: Bricoleur Press.

Kendon, Adam. 1997. “Gestures”. Annual Review of Anthropology, 26:109-128.

Knorr-Cetina, Karin. 1983. "The Ethnographic Study of Scientific Work: Towards a Constructivist Interpretation of Science”. In: Karin Knorr-Cetina \& Michael Mulkay (eds.). Science Observed: Perspectives on the Social Study of Science. London: Sage. pp. 115-140.

Lakoff, George \& Johnson, Mark. 1980. Metaphors We Live by. Chicago: University of Chicago Press.

1999. Philosophy in the Flesh: the Embodied Mind and its Challenge to Western Thought. New York: Basic Books.

Latour, Bruno. 1993. We Have Never Been Modern. Cambridge, MA: Harvard University Press.

1999. Pandora's Hope: an Essay on the Reality of Science Studies. Cambridge, MA: Harvard University Press.

Latour, Bruno \& Woolgar, Stephen. 1986. Laboratory Life: the Construction of Scientific Facts. Princeton: Princeton University Press.

Levi-Strauss, Claude. 1973. Tristes Tropiques. London: Johnathan Cape.

Lucas, Gavin. 2005. The Archaeology of Time. London: Routledge.

McNeil, David. 1992. Hand and Mind: What Gestures Reveal about Thought. Chicago: University of Chicago Press.

Meskell, Lynn \& Preucel, Robert W. 2004. A Companion to Social Archaeology. Chicester: Wiley-Blackwell.

Murray, Tim. 1999. Time and Archaeology. London: Routledge.

Nuñez, Rafael E. \& Sweetser, Eve. 2006. "With the Future Behind Them: Convergent Evidence from Aymara Language in the Crosslinguistic Comparison of Spatial Construals of Time”. Cognitive Science, 30:401-450.

Olivier, Laurent. 2004. "The Past of the Present: Archaeological Memory and Time". Archaeological Dialogues, 10(2):204-213.

. 2011. The Dark Abyss of Time: Archaeology and Memory. Lanham: AltaMira Press. 
Polanyi, Michael. 1983. The Tacit Dimension. Gloucester: Peter Smith.

Reid, J. Jefferson; Schiffer, Michael B. \& Rathje, William L. 1975. "Behavioral Archaeology: Four Strategies”. American Anthropologist, 77(4):864-869.

Sapir, Edward. 1985. "Symbolism". In: . Edward Sapir's Selected Writings in Language, Culture and Personality. Berkeley: University of California Press. pp. 564-568.

Schanks, Michael \& Tilley, Chris. 1987. Social Theory and Archaeology. Cambridge: Polity. Sheets-Johnstone, Maxinne. 1999. The Primacy of Movement. Philadelphia: John Benjamins. Simonetti, Cristián. 2012. Encountering Depths across Surfaces: Time and Space in Archaeology. Unpublished doctoral thesis, University of Aberdeen.

. 2013. "Between the Vertical and the Horizontal: Time and Space in Archaeology". History of the Human Sciences, 26(1):90-110.

. 2014. "Feeling Forward Into the Past: Depth and Surfaces in Archaeology". Time \& Mind, 8(1): in press. http://www.doi.org/10.1080/1751696X.2014.992686

Thomas, Julian S. 1996. Time, Culture and Identity: an Interpretative Archaeology. London: Routledge. 2004. "Archaeology's Place in Modernity". Modernism/Modernity, 11(1):17-34.

Tilley, Chris. 1994. A Phenomenology of the Landscape: Places, Paths and Monuments. Oxford: Berg.

Trigger, Bruce. 1984. "Alternative Archaeologists: Nationalist, Colonialist, Imperialist". Man, 19(3):155-170. 2006. A History of Archaeological Thought. Cambridge: Cambridge University Press.

Turner, Victor. 1967. The Forest of Symbols: Aspects of Ndembu Ritual. Ithaca: Cornell University Press.

Whorf, Benjamin Lee. 1959. Language, Thought and Reality. Cambridge: MIT Press.

Yarrow, Thomas \& Garrow, David. 2010. Archaeology and Anthropology: Understanding Similarities, Exploring Differences. Oxford: Oxbow Press. 


\section{Resumo}

A compreensão do passado na arqueologia é muito influenciada pela maneira como o tempo é espacializado nesta disciplina. Baseado em trabalho de campo etnográfico entre arqueólogos, este artigo examina o uso das expressões sobre o tempo e a relação entre palavras e gestos. Demonstra-se que conceitos importantes na disciplina referem-se à experiência em face de um passado profundo sob o solo e de uma temporalidade vertical, que evolui do fundo ao topo. A analise traz ideias sobre a relação entre movimento corporal e conceitualização diferentes daquelas da linguística cognitiva, demonstrando que os conceitos não são entidades abstratas, mas são co-emergentes e contínuos com as maneiras como os arqueólogos se apropriam do ambiente gravitacional na prática. Isto tem implicações importantes para se compreender como o conhecimento é constituído nas ciências que escavam o passado, que desafia algumas compreensões difundidas do conhecimento disciplinar como entidades autocontidas que se destacam de um encontro ecológico com o mundo das coisas.

Palavras-chave: arqueologia, tempo, conceitos, cronologias, gesto.
The understanding of the past in archaeology is much influenced by how time is spatialized within the discipline. Based on ethnographic fieldwork among archaeologists, this article examines the use of time expressions and the relationship between speech and gestures. It shows that concepts important for the discipline refer to the experience of facing a past deep underneath the ground and a temporal verticality that runs from bottom to top. The analysis provides insights into the relationship between corporeal movement and conceptualization that contrast with those of cognitive linguistics by showing that concepts are not abstract entities but are co-emergent and continuous with the ways archaeologists appropriate their gravitational environments through practice. This proves to have serious implications for understanding how knowledge is constituted in sciences that excavate the past, which seriously challenges some widespread understandings of disciplinary knowledge as self-contained entities that are detached from an ecological encounter with the world of things.

Keywords: archaeology, time, concepts, chronologies, gesture. 